\title{
Psychological Adjustment of Aging Vietnam Veterans: The Role of Social Network Ties in Reengaging with Wartime Memories
}

\author{
Christina M. Marini ${ }^{a} \quad$ Katherine L. Fiori ${ }^{a} \quad$ Janet M. Wilmoth ${ }^{b}$ \\ Anica Pless Kaiser ${ }^{c, d}$ Lynn M. Martire \\ ${ }^{a}$ Department of Psychology, The Gordon F. Derner School of Psychology, Adelphi University, Garden City, NY, USA; \\ ${ }^{b}$ Department of Sociology, Aging Studies Institute, Syracuse University, Syracuse, NY, USA; ' National Center for \\ PTSD, VA Boston Healthcare System, Boston, MA, USA; ${ }^{d}$ Department of Psychiatry, Boston University School of \\ Medicine, Boston, MA, USA; ${ }^{e}$ Department of Human Development and Family Studies, The Pennsylvania State \\ University, State College, PA, USA
}

\section{Keywords}

Veterans - Combat exposure - Trauma reengagement .

Social networks Social support

\begin{abstract}
It is projected that by 2020 there will be 8.7 million veterans over the age of 65 years, more than half $(64 \%)$ of whom served during the Vietnam War. The effects of military service on mental health and well-being may be more pronounced later in life among those who served in Vietnam than prior cohorts of veterans. Many veterans confront and rework their wartime memories later in life in an attempt to find meaning and coherence, engaging in a process referred to as Later-Adulthood Trauma Reengagement (LATR). LATR often occurs in the context of other stressors that are a normative part of aging, such as role transitions (e.g., retirement), declines in physical health, and the death of close others (e.g., spouses), perhaps because these events trigger reminiscence. Importantly, LATR may result in either positive (e.g., acceptance) or negative (e.g., distress) psychological outcomes. It has been suggested that the presence of social/ environmental resources, including socioemotional sup-
\end{abstract}

port, may aid veterans in successfully navigating LATR. We, therefore, review relevant areas of research to delineate the role that various layers of social context may play in helping - or hindering - aging Vietnam veterans as they navigate LATR in the context of normative late-life stressors. We conclude by offering fruitful directions for future research and applied implications for intervention efforts.

(c) 2019 S. Karger AG, Basel

\section{Introduction}

The US Veteran population - much like the larger population - is rapidly aging. It is projected that by 2020 there will be 8.7 million veterans over the age of 65 years, more than half $(64 \%)$ of whom served during the Vietnam War [1]. As our largest cohort of veterans shifts to the Vietnam era (1964-1975), veterans over the age of 65 are increasingly diverse, both in terms of sex and race/ ethnicity. Vietnam era veterans also have a diverse set of military experiences. Only about half (46\%) of Vietnam era veterans served inside Vietnam or in theatre [2]. These Vietnam veterans face unique threats to their

\section{KARGER}

(C) 2019 S. Karger AG, Basel

karger@karger.com

www.karger.com/ger
Christina Marini

1 South Avenue

Blodgett Hall, Room 212

Garden City, NY 11530 (USA)

E-Mail cmarini@adelphi.edu 
mental health and well-being stemming from the nature of combat engagement in a war without a clear front line and antiwar sentiment [1]. However, the majority of Vietnam veterans demonstrate profound psychological resilience. Epidemiological studies conducted 40 years after the war indicate that $85 \%$ of Vietnam veterans did not meet the criteria for posttraumatic stress disorder (PTSD) [3]. However, Vietnam veterans exposed to combat are more likely than those who were not exposed to combat to have PTSD, with some estimates indicating that more than a quarter (27\%) of veterans who experienced heavy combat manifested PTSD-related symptoms by age 36 years [4]. In fact, combat exposure has been shown to be a key factor driving differences in veterans' mental and physical health across the life course [5]. Notably, these estimates do not include veterans who are coping with subthreshold levels of PTSD or other trauma-related symptoms diagnosed as a different disorder, such as major depression, both of which also likely impact veterans' quality of life.

Because Vietnam veterans are just now entering later life, our understanding of how their (potentially traumatic) combat experiences are (or will be) tied to their laterlife mental health and well-being is limited. However, Vietnam veterans already have poorer self-rated health and more chronic health conditions around retirement age than those who served during World War II [6]. Building on the concept of Later-Adulthood Trauma Reengagement (LATR) by Davison et al. [7], we, therefore, focus our review on aging Vietnam veterans' mental health and well-being as they cope both with previous wartime memories and normative developmental stressors that accompany aging (e.g., declines in physical health). We expand on their framework by honing in on the role that social network ties may play in helping Vietnam veterans process their previous wartime experiences later in life.

\section{Combat Exposure and Later-Life Mental Health and} Well-Being

Much of the contemporary research on long-term effects of combat exposure can be traced back to Elder and Clipp's [8] seminal study of World War II and Korean conflict veterans. In midlife (i.e., 20 years after serving), high-combat veterans were more likely than low- or moderate-combat veterans to report that their military service enhanced their ability to cope with adversity. When comparing clinical ratings of psychological functioning during adolescence to those in midlife, only high-combat veterans experienced a significant increase in resilience, with low- and moderate-combat veterans experiencing no significant change. Later in life (i.e., 40 years after service), however, a different picture emerged as high-combat veterans were more likely to experience painful memories and symptoms of stress than their low- and moderatecombat veteran counterparts. Similarly, utilizing longitudinal data from the Health and Retirement Study (HRS), Wilmoth et al. [6] found that male veterans who served during wartime experienced both better physical health around retirement age as well as steeper age-related declines in health compared to veterans who did not serve during wartime. Together, these findings illustrate the potential for effects of wartime service to vary across the life course, with positive effects experienced through midlife declining with increasing age.

In addition to the potential for positive effects of combat exposure to deteriorate later in life, negative effects (particularly psychological ones) may be amplified. In fact, mean levels of male and female Vietnam veterans' self-reported PTSD symptoms 40 years after the war ended (when veterans were in their 50s and 60s) have been shown to be significantly higher than they were 25 years earlier [3]. This may be because retired veterans likely have less structure and responsibilities than working aged veterans. Retired veterans may, therefore, have both more time to think about their past wartime experiences and fewer distractions from thinking about them. Older veterans may also find it increasingly difficult to intentionally suppress unwanted memories because inhibitory control declines with age [9].

Feelings of loss and powerlessness associated with prior combat-related experiences may also resurface due to other normative stressors that accompany aging (e.g., declining health), thereby triggering reminiscence. Thus, stressors and transitions that accompany aging may act as "losses" that trigger the development of Late-Onset Stress Symptomology (LOSS) [10]. LOSS is thought to occur among veterans who successfully adjusted in the aftermath of their military service, but went on to experience increases in thoughts and memories, along with possible distress, related to their combat experiences in later life. This idea is similar to a pattern of functioning discussed by Elder and Clipp [8] in which unresolved conflict associated with wartime service may lay dormant, only to resurface at a future time characterized by circumstances that resemble the unresolved conflict. Accordingly, LOSS has been negatively associated with physical health and positively associated with concerns about retirement and later-life stressors [11]. 
Fig. 1. Conceptual model of the role of social network ties in aging Vietnam veterans.

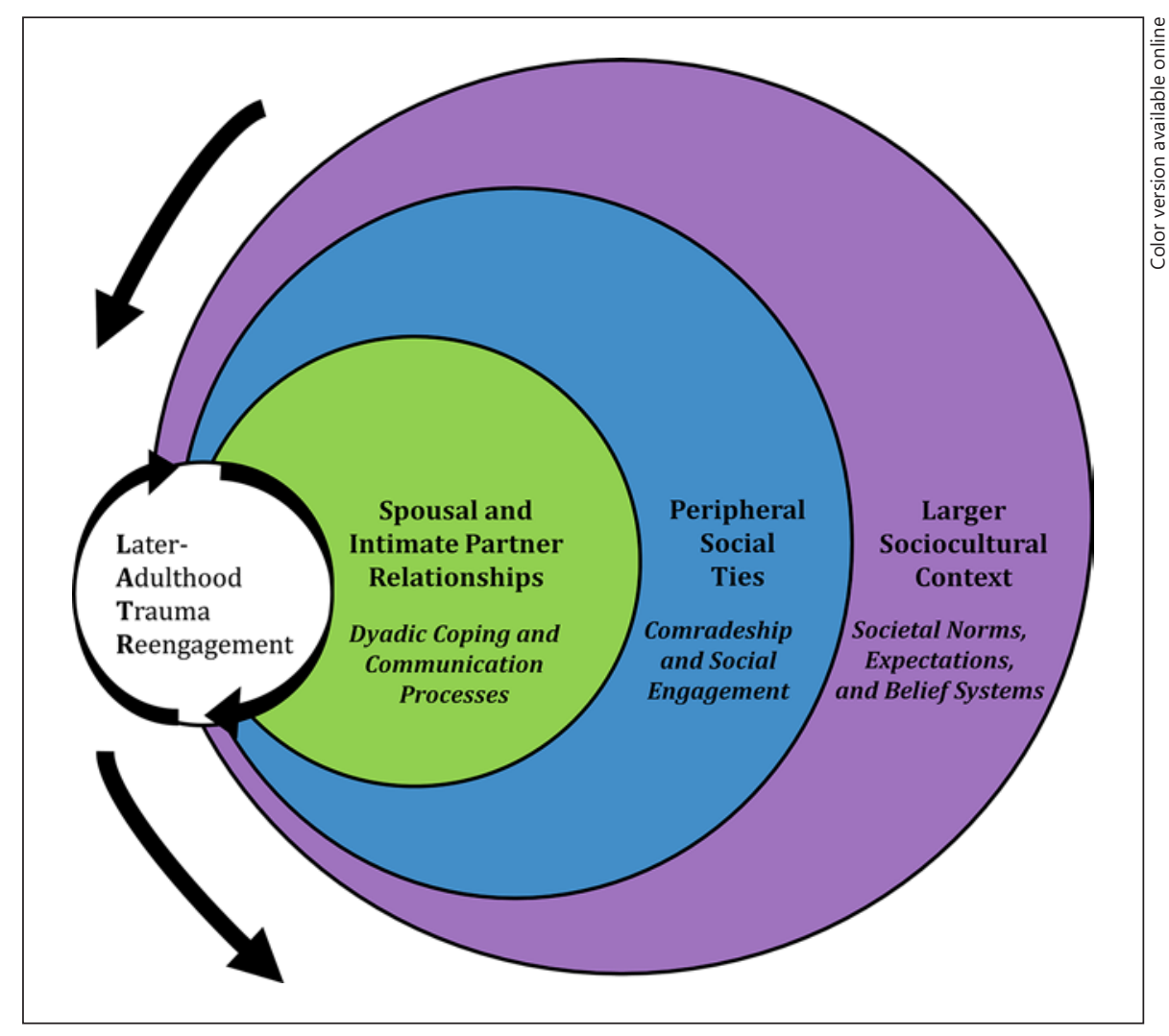

\section{Later-Adulthood Trauma Reengagement}

Nearly a decade after introducing the concept of LOSS, Davison et al. [7] broadened their perspective to encompass ideas from the gerontology and resilience literatures, thereby renaming their concept Later-Adulthood Trauma Reengagement. Viewed as a normative, developmental process (much like that of a life review), they posit that veterans likely confront and rework their wartime memories in an attempt to find meaning and coherence, particularly as they navigate later-life stressors. Similar to LOSS, LATR can be seen in older combat veterans facing normative challenges of aging (e.g., retirement, bereavement, or health changes). In particular, normative physical changes (e.g., decreased mobility or sensory changes such as hearing and vision loss) and cognitive decline can trigger increases in intrusive wartime memories and emotions associated with trauma exposure, which can, in turn, lead to increased distress as well as PTSD symptoms and related behavior (such as increased hypervigilance associated with problems hearing or seeing) [12]. The ability to engage in LATR, which is a cognitive task, may also be impacted by cognitive changes that occur with aging. For example, it is possible that veterans with more severe cognitive impairments may have difficulty engaging with others to rework or reevaluate their wartime memories.

Importantly, LATR is thought to lead to positive (e.g., acceptance) or negative (e.g., distress) outcomes depending on the presence of both intrapersonal (e.g., selfesteem) and social/environmental (e.g., social support) resources. Because LATR is considered a normative process, the vast majority of veterans likely experience this process with the support of family and friends [7]. We, therefore, focus our review on the role that social network ties may play in helping Vietnam veterans successfully navigate LATR. Research on aging more broadly has posited that "current support and feedback from social network members is likely to come into play as older adults engage in the process of introspection" [13, p. 618]. Further, trusted confidants may help older adults "process troubling emotions and point out blind spots in their selfperceptions as well as self-serving biases in the autobiographical reconstruction that takes place during this developmental stage" [13, p. 618].

We therefore posit that LATR is a process that unfolds (at least partially) within a social context. Thus, in Figure 1, 
LATR is illustrated as a circle that partially overlaps with 3 other concentric circles. The smallest circle includes spousal and intimate partner relationships, which we consider the most proximal social context. The next circle includes more peripheral social ties, such as friends and comrades. Finally, the largest circle, which fully encompasses the others, is representative of the larger sociocultural context. In the sections that follow, we first review existing literature on aging veterans and social support more broadly. Then, we consider the role of spousal/intimate partner ties, other social network ties, and the larger sociocultural context in shaping how aging Vietnam veterans engage in LATR, and whether LATR results in positive or negative psychological outcomes.

\section{Aging Vietnam Veterans: Perceived Social Support and Well-Being}

Multiple studies have found that current perceived social support is a protective factor for veterans both 20 years [14, 15] and 40 years [16] after serving in Vietnam. By utilizing data from the National Vietnam Veterans Readjustment Study (NVVRS) and its more recent followup, the National Vietnam Veterans Longitudinal Study (NVVLS), the aforementioned findings are valuable in that they are nationally representative of veterans. However, the focus on PTSD and general measures of social support in these studies limit their ability to speak to specific social support processes that may be protective for Vietnam veterans' mental health and well-being.

Research with World War II and Korean conflict veterans indicates that specific types of social support can either promote or hinder veterans' processing of traumatic memories [17]. While in their 80 s, some veterans in the qualitative study by Burnell et al. [17] reported that traumatic wartime memories came back to them later in life. However, they felt like they successfully reconciled them, in part by communicating about these experiences with family members. Although some reported avoiding communication with family in the immediate aftermath of their service, communication improved later in life when veterans felt like their experiences were important and meaningful. Other veterans did not successfully reconcile their wartime memories. These veterans consistently avoided communication with family members across the life course. Other research has similarly found that desirable appraisals of military service (e.g., service broadened one's perspective) are positively associated with the extent to which veterans speak to family about their experiences, both of which predict lower levels of PTSD later in life [18]. Thus, communication about wartime experi- ences appears to be a specific process that promotes veterans' well-being.

Although the aforementioned studies provide a valuable foundation, they do not consistently consider the various ways in which others may respond to service members' disclosures of wartime experiences later in life. We posit that the ways in which others respond to such disclosures will play a pivotal role in the degree to which aging Vietnam veterans successfully reconcile their past experiences. Thus, there is a clear need for process-oriented research focused on communication about Vietnam veterans' past combat- or trauma-related experiences as they navigate LATR. In order to generate fruitful directions for future research and clinical/ intervention implications with aging Vietnam veterans, we will consider the role that both spouses (and intimate partners) and other social network ties (e.g., friends and comrades) may play in helping Vietnam veterans navigate LATR, as well as the role of larger sociocultural factors.

\section{The Role of Spouses and Intimate Partners}

Several theoretical frameworks underscore the potential for spouses to influence the psychological adjustment of aging combat veterans, particularly those coping with wounds and injuries [19]. For example, both dyadic coping and intimacy process models posit that spousal communication is a key relationship process that can either ameliorate - or exacerbate - individual distress. Dyadic coping models include individual stress communication and empathic or minimizing spousal responses to such communication as key processes to explain psychological adjustment to stress [20]. Intimacy process models include a similar focus on disclosure-responsiveness links, such that individuals' disclosure of stress, coupled with their spouse's responsiveness (e.g., making individuals feel understood), promotes well-being [21].

In line with dyadic coping and intimacy process models, recent research with service members and veterans of the post 9/11 cohort has identified disclosure as a key determinant of service members' adjustment. A lack of emotional disclosure of deployment experiences to one's spouse has been identified as a mechanism through which service members' symptoms of posttraumatic stress are associated with lower levels of service members' and spouses' relationship satisfaction [22]. Military couples who engage in trauma disclosure have also been shown to be more cohesive and aware of one another's needs [23]. Thus, for service members, confiding in one's spouse may "facilitate successful processing of the traumatic event by 
allowing the disclosure of emotions, helping the individual to learn to tolerate aversive feelings, providing support for adaptive coping, and providing direct assistance in finding meaning and benefit in the experience" [19, p. 217]. Holding back deployment-related distress from one's spouse has similarly been shown to be negatively associated with service members' psychological wellbeing both during, and in the immediate aftermath of, deployment [24].

The manner in which service members' spouses respond to their disclosures and concerns also appears to be an important factor. For instance, spousal minimization of service members' concerns (e.g., acting like they do not notice service members' worries) during deployment has been associated with higher levels of service members' depressive symptomology after deployment [25]. If service members view their spouses' minimizing responses as unsupportive, they are less likely to disclose their emotions to them in the future. In fact, service members who perceive their spouses to be more supportive are more likely to disclose their combat-related experiences to them, which in turn predicts lower levels of PTSD symptoms [26]. Such findings have led to the development of newer couple-focused interventions that target veterans' disclosure of trauma-related emotions/ memories and spouses' empathic communication and acceptance [27].

The aforementioned research is largely focused on the post 9/11 cohort during, or in the immediate aftermath of, wartime service. Although informative, such findings may not generalize to aging Vietnam veterans. Research conducted among the post $9 / 11$ cohort is focused on younger service members who are, primarily, still serving in the military, which may thwart service member disclosure of traumatic memories to their spouses in fear of worrying them, especially if there is a threat that they will deploy again [28]. Because of their age, research with post 9/11 service members also does not encompass veterans who are engaging in reminiscence and life review as part of a normative developmental process. Thus, from a life course perspective, an examination of spousal communication among the post $9 / 11$ cohort is not situated within the correct developmental time frame.

Given the normative stressors that accompany aging that likely trigger LATR [7], it is important to examine couples' communication about wartime experiences among aging Vietnam veterans and their spouses. For these older veterans, it is important to consider their complete marital histories. Vietnam era service members tended to get married at older ages after separating from active duty service [29], and combat-exposed Vietnam veterans have been shown to experience higher levels of marital instability across the lifespan [30]. If the veteran's current spouse was not exposed to their wartime service, then the spouses' lack of knowledge or understanding of their experiences may complicate spousal communication surrounding veterans' wartime memories.

Spousal communication about veterans' traumatic experiences later in life may further be complicated by veterans' current physical health. Combat-exposed Vietnam veterans are at an increased risk of developing chronic conditions later in life, including asthma, arthritis/rheumatism, and lung diseases [30]. Declining physical health may trigger aging veterans to reengage with their wartime experiences [7]. Couples may therefore be tasked with concurrently processing strong emotions surrounding veterans' previous wartime experiences and current physical symptoms, thus perhaps compounding the significance of disclosure-responsiveness links among later-life couples. In fact, when coping with cancer, veterans currently exhibiting symptoms of combat-related PTSD experience more cancer-related distress than those not currently experiencing combat-related PTSD symptoms [31].

Individual disclosure and spousal responsiveness appear to be important predictors of psychological adjustment among older couples coping with one spouse's (i.e., the patient's) illness. Research conducted with samples of older couples coping with health-related stressors indicates that patients' psychological well-being is compromised when their disclosures are socially restricted [32]. Findings from a study of couples coping with a lupus flare-up, for example, indicated that wives' restrictive communication (e.g., changing the topic away from husbands' concerns) was associated with higher levels of husbands' depressive symptoms [33]. This study further indicated that husbands' perceptions of their wives' emotional responsiveness (or lack thereof) partially mediated the positive association between wives' restrictive communication and husbands' depressive symptomology. In other words, when wives utilized more restrictive communication behaviors, husbands reported that their wives were less emotionally responsive, which in turn elevated husbands' distress. Thus, by better understanding the nature of disclosure-responsiveness links among aging Vietnam veterans and their spouses, we may gain insight into the role that spouses play in helping veterans navigate not only LATR, but also their adjustment to chronic health stressors that will likely increase in number and severity as they continue to age. 


\section{The Role of Other Social Network Ties}

Social network members other than spouses also likely play a role in assisting aging veterans process wartime memories. According to the Convoy Model of social relations [34], social networks are "convoys" that are shaped throughout the lifespan by personal characteristics and individual circumstances, and these broad social networks influence well-being through the support that the network members provide. Networks tend to shrink in size as adults age, for both deliberate and nondeliberate reasons $[35,36]$. However, more peripheral or "weak" ties tend to shrink disproportionally compared to emotionally closer ties [35]. The Socioemotional Selectivity Theory explains these changes by positing that, as individuals age, they perceive time as more limited [37]. The sense that they have less time to live then alters individuals' motivations for social engagement, such that they prioritize spending time with their closest social ties. For veterans, although normative declines in social network size may diminish opportunities for identity maintenance through reminiscence [38], a developmental focus on meaning-making may motivate them to engage in LATR with former comrades, with whom they have a unique shared understanding of wartime experiences.

Age-related network changes tend to be associated with life events, such that normative life events (e.g., retirement, deaths of friends, declining health of spouse) drive changes in social networks [36]. Importantly, these life events that are instrumental in shaping the networks of older adults are often the very same life events that trigger reminiscence and, among older veterans, trigger LATR as well [7]. For example, retirement tends to be accompanied by rather dramatic changes in the social network [34]. Although retirees are deprived of daily social interactions with work colleagues, this adjustment may translate into a strengthening of family and friend roles. For veterans, retirement may provide not only more time and fewer distractions to think about wartime experiences (as mentioned earlier), but may also provide opportunities to develop relationships with other veterans through veteran service organizations, such as the Veterans of Foreign Wars and the American Legion. These organizations may allow veterans to foster close relationships with comrades and also to build a network of weak ties, which, because they require less time and effort to sustain, can provide functions that close ties often do not (e.g., novelty, information resources, diverse activities) [39]. In fact, veteran organizations appear to provide a way for older veterans to maintain meaningful social connections in everyday life in spite of losses (e.g., due to retirement, death of family members) and other barriers to close relationships [17, 40].

Veteran organizations can also provide a forum for veterans to develop narratives about their wartime experiences, and perhaps process traumatic recollections [41]. Although focused primarily on World War II male veterans [41] and Falklands War veterans [28, 17], qualitative research indicates that veterans rely heavily on former comrades and veteran organizations to cope with their wartime memories. Older male veterans have described how their connections with comrades and peers within veteran organizations have helped them "define their identity" [40, p. 1467] while providing a safe and secure environment, emotional support, tangible assistance, and meaningful activities [42]. Given that reminiscence focused on identity (i.e., using memories to identify a pattern of coherence in one's life) has been positively linked to psychological well-being [43], these interactions may aid veterans in spite of the lack of direct processing of traumatic experiences.

In addition to the acquaintances that veterans may meet through veteran organizations, veterans' social convoys almost always include close friends in the form of comrades [41]. Diverse social networks (i.e., those that include family and friends) are positively linked to well-being in the general population of older adults [34, 44], and aging individuals in friend-focused networks tend to have better mental health outcomes than those in family-focused networks (perhaps in part because family relationships are generally obligatory, whereas friend relationships are optional) [44]. Thus, the inclusion of comrades in veterans' social networks is likely beneficial, and, in fact, comradeship appears to play a unique role that goes beyond the benefits of typical friendships [41]. Having both comrades and veteran organizations as outlets for discussing wartime memories may have positive implications not only for veterans but also for their spouses. By outsourcing some of the emotional work of LATR to weaker, less emotionally invested ties, or to former comrades who have a unique shared understanding of war, veterans may relieve their spouses of some of the emotional burden of such work.

Another life event that tends to shift the make-up of social networks is widowhood. Widowhood may lead to an initial decrease in social contacts for older adults, but then widows and widowers tend to receive more support from children and friends, as well as see friends more regularly, than their married, divorced, or single coun- 
terparts [34]. Although men are much less likely to experience widowhood than are women [45], the loss of a wife can be particularly traumatic for older male veterans who may have depended quite heavily on their spouse for emotional and/or practical support after returning from war and over the course of their adult lives [41]. That being said, even frail older male veterans compensate for being widowed and living alone by relying on adult children, other relatives, and/or friends [46]. However, just as in the general population, declining health may lead to withdrawal from beneficial diverse and friend-focused networks [47]. Thus, veterans with health problems may have a particularly difficult time maintaining or replacing lost network ties [46].

\section{Role of the Sociocultural Context}

The majority of what is known about older veterans and their social support networks is based on World War II and Korean conflict veterans. This extant research captures veterans at the right developmental stage (i.e., later in life) but may not generalize to Vietnam veterans. There is substantial variation across cohorts in the historically based sociocultural circumstances surrounding military service. For men in the United States who came of age during the middle of the 20th century, military service was a normative part of the transition to adulthood. Rates of military service were over $50 \%$ for male cohorts born between 1915 and 1935, with rates over 70\% for men born between 1919 and 1927 (who served primarily during World War II) [48]. Men who served during this time period tended to receive a warm public reception at the end of their service and were generally celebrated as war heroes. Collectively, these men from the "Good Warrior" cohort had access to relatively generous GI Bill benefits, achieved higher educational and socioeconomic attainment, experienced greater marital stability, and had better health outcomes than nonveterans. Similarly, veterans from the Korean War and Cold War eras tended to benefit from their service [49].

In contrast, the benefits of military service did not materialize for veterans of the Vietnam War for a number of reasons. From the start, there was skepticism about American involvement in the conflict and the poor implementation of the draft further undermined public support [50]. Service members often experienced a hostile reception when they returned from the war and many found it difficult to reintegrate into civilian life, particularly if they had experienced combat [4]. Compared to previous veteran cohorts, Vietnam War veter- ans did not experience as many returns to service in terms of educational and socioeconomic attainment, marital stability, or health outcomes [5]. This may be due in part to the macroeconomic and labor market conditions that the Baby Boom cohort experienced as they transitioned into adulthood. Early in their careers, the members of this large cohort had to compete for entry level jobs during the economic recessions of the 1970s and 1980s, which made it more difficult for this cohort to experience upward socioeconomic mobility than prior cohorts [5].

Consequently, Vietnam veterans may not be as socially integrated as veterans from prior cohorts. They may therefore not have sufficient social networks within which they can engage in LATR. For example, evidence suggests that Vietnam veterans who experienced warrelated trauma were particularly likely to perceive that they have low levels of social support (especially emotional support), at least through their mid-30s [51]. Whether such low levels of support extend to later in life, however, remains unknown. If so, this may generate additional challenges for aging Vietnam veterans, both in terms of engaging in LATR more broadly and in utilizing social network ties for processing wartime memories. Even assuming the presence of a robust social network, the experiences of wartime veterans in general, and Vietnam veterans in particular, may lead to some resistance in disclosing wartime experiences to civilians. As such, Vietnam veterans may feel more comfortable reminiscing with former comrades and other veterans than discussing wartime memories with family and nonwartime friends. More troubling is the possibility that veterans with traumatic memories who rely on commonly used avoidant coping strategies may not only stymie the process of LATR but also further alienate themselves from their social network ties [40]. Given the difficulties Vietnam veterans in particular may have with utilizing their social networks to help them process wartime memories, some veterans may benefit from seeking out more formal services. Brady et al. [52] suggested that providers working with older combat veterans screen for LATR, along with PTSD, to identify veterans who might benefit from intervention.

In a discussion of sociocultural context, it is important to recognize that Vietnam veterans were more diverse, both in terms of sex and race/ethnicity, than their predecessors [1]. We can only speculate about the role of social network ties for the well-being of aging female veterans engaging in LATR. Gender differences seen in the social relationships of the general population of adults across 
the lifespan (e.g., that women report having larger and more multifaceted social networks than men) may (or may not) also be reflected in the relationships of veterans [34]. For instance, it is notable that Vietnam and postVietnam female veterans report lower levels of perceived social support than female veterans from other eras [53]. Furthermore, research shows that older female veterans share collective perceptions of wartime experiences with close female friends at home rather than at meetings of veteran organizations [40]. Thus, protective effects of belonging to veteran organizations may be gender specific. These protective effects may also be race/ethnicity specific. However, little is also known about how social network ties aid in the process of LATR for veterans from racial/ethnic minority groups.

Engagement in LATR is also likely challenging for older lesbian, gay, bisexual, and transgender (LGBT) veterans who served prior to the 2010 repeal of the "Don't Ask, Don't Tell" policy, which suspended the practice of questioning recruits about homosexuality, but reinforced many discriminatory practices based on sexual orientation and gender identity that had been in place since World War II [54]. LGBT older adults often have more limited social care networks and tend to rely more on friends than family [55]. However, there is limited evidence about the social networks of LGBT veterans and the extent to which they participate in veteran organizations or socialize with comrades. LGBT individuals report more lifetime and day-to-day experiences with discrimination, which are associated with poor mental health outcomes [56]. Despite this, they may be reluctant to seek formal assistance due to concerns about negative reactions among health care professionals. A recent study of LGBT veterans found that $24 \%$ had not disclosed their LGBT identity to any VA provider, and $28 \%$ reported that the VA was unwelcoming to them as LGBT veterans [57]. Attenuated informal social networks in conjunction with weak ties to formal health care providers is potentially problematic for older LGBT veterans experiencing LATR and, along with the previously discussed challenges faced by veterans who are female and/ or racial/ethnic minorities, warrants consideration in future research.

\section{Conclusions and Recommendations}

LATR is a process that unfolds within a social context [7]. Both spouses and other social network members (e.g., friends and comrades) play a pivotal role in the de- gree to which veterans' re-engagement with wartime memories later in life results in psychological growth versus distress. In addition to these social network ties, the process of LATR is influenced by larger sociocultural factors, including public support for the war effort, the reception that military personnel receive when returning to civilian life, and the socioeconomic returns to military service. Future research is therefore needed to help us to better understand the experiences of aging Vietnam veterans and key members of their social networks. Such research should focus on late adulthood to capture veterans' experiences at the correct developmental time, while also taking into account their unique set of sociocultural experiences. Because the Vietnam cohort is currently entering later life, the time to engage with them is now. As stated by London, "Failure to act now to enhance the capacity of the social science research community to study military service, aging, and the life course will represent a missed opportunity" [5, p. 212].

Leveraging data from existing sources, including nationally representative and longitudinal datasets, is an important first step. The HRS, for example, added a Veterans Mail Survey in 2013 that was sent to any HRS respondent who reported serving in the active military. The survey includes detailed information about veterans' military experiences. No studies to our knowledge have linked data from the 2013 Veterans Mail Survey to that of the psychosocial questionnaires included in the HRS to examine ties between aging veterans' psychological well-being and the quality of their social relationships later in life. Analysis of longitudinal data like the HRS is essential to address the potential reciprocal relationship between psychological well-being and social relationships. While there are numerous studies that demonstrate the positive impact that social support can have on psychological outcomes, it is also the case that psychological well-being supports the establishment and maintenance of supportive relationships [58]. Thus, aging veterans who have supportive others who can help them process wartime memories as they engage in LATR may have better psychological outcomes in part because they had more psychological resources. As such, to fully understand the relationship between social support and psychological well-being among aging veterans, it is critical to have measures of both constructs at multiple points in time and to employ analysis techniques that are able to disentangle reciprocal effects.

Large-scale longitudinal data can also be helpful in isolating the effects of potentially confounding variables, to the extent that the data contain adequate measures of 
relevant constructs. For veterans engaging in LATR, it would be important to include controls for military service experiences, such as combat experience, exposure to the dead, wounded, and dying, service-related injuries, and service-connected disability rating. Furthermore, large-scale data sets might be able to elucidate the mechanisms through which supportive network ties may promote aging veterans' mental health and well-being as they make sense of their wartime experiences. For example, measures of relationship quality, loneliness, and health behaviors (e.g., sleep, diet) could all be assessed as potential mechanisms explaining this process.

While taking advantage of nationally representative, longitudinal datasets has many advantages (e.g., increased generalizability, comparisons between veterans and nonveterans), it also comes with costs, most notably a lack of specificity, particularly about veterans' processing of wartime memories and aspects of their social networks. Datasets also often lack critical preservice measures that would enable researchers to address methodological issues related to selection into military service in general and into combat roles in particular [59]. Numerous recommendations have been made regarding improving data collection, which we will not reiterate here [60]. Instead, in the interests of enhancing our understanding of LATR, we posit that future data collection efforts focus primarily on the communication processes that unfold between aging Vietnam veterans and members of their social networks to better understand the role that various social ties play in helping veterans make meaning of their wartime experiences and successfully navigate LATR. Importantly, an abbreviated, quantitative measure of LATR has been validated and can therefore be implemented in future studies focused on aging veterans [52].

We suggest that such research would be valuable in informing future LATR-focused interventions, perhaps by highlighting the value of couple-, friend-, and comrade-focused components that would promote veterans' engagement and successful resolution of LATR in the context of supportive social networks. Psychoeducation around the Vietnam veteran experience may be useful for nonveteran friends or family members to enhance knowledge, awareness, and support. Veterans experiencing LATR may also benefit from engaging in discussions with other veterans to validate and share their experiences, promote meaning making and posttraumatic growth, build coherence, and work to integrate their military experiences into their life narratives.

In addition, a focus on developing or strengthening positive coping strategies and hearing about other veter- ans' experiences may help veterans to navigate through the LATR process. Many veterans may engage with and successfully resolve LATR using mainly their informal social networks, whereas other veterans may find participating in a more formal provider-facilitated group intervention to be more beneficial [7]. The VA is a prime location from which to offer such intervention efforts as they can be integrated with other services that veterans may already be receiving. The VA also provides veterans with opportunities to socialize with other veterans in informal (e.g., chatting in waiting areas or cafeterias) and formal (e.g., group-based interventions) ways. In addition, for veterans who are more socially isolated and either have small social networks or are more hesitant to discuss their military experiences and the impact of these experiences, clinical outreach efforts are needed to identify and offer services, as these veterans may benefit more from formal LATR interventions. However, given the majority of older veterans receive health care outside of the VA system, it is also important to develop community-based LATR interventions that involve health care providers and social service organizations that are not explicitly military or veteran connected. Programs that reach a broad cross section of the population will help to ensure that aging Vietnam veterans who are continuing to process their wartime experiences receive the support they need to optimize their psychological well-being as they move through later life.

\section{Statement of Ethics}

No approval was required to complete this nonempirical manuscript.

\section{Disclosure Statement}

The views expressed in this manuscript are those of the authors and do not necessarily represent the official viewpoint of the US Department of Veterans Affairs. The authors have no conflicts of interest to declare.

\section{Funding Sources}

This work was supported by the National Institutes of Health (T32 AG049676) and the US Department of Veterans Affairs (Rehabilitation Research and Development Service award IK2 RX001832-01A2 to A. Pless Kaiser).
Marini/Fiori/Wilmoth/Pless Kaiser/ Martire 


\section{Author Contributions}

Christina M. Marini contributed the overall conceptualization of the manuscript, as well as expertise on marital/intimate partner relationships and military couples more specifically. Katherine L. Fiori contributed expertise on social network ties outside of marriage. Janet $\mathrm{M}$. Wilmoth contributed expertise on sociocultural in- fluences. Lynn M. Martire provided expertise on aging couples and aging theories. Please note that Anica Pless Kaiser was added as an author at the revision stage. Her clinical expertise on clinical/intervention implications and the effects of military-connected trauma later in life was necessary in order to include a discussion on clinical implications as suggested by the reviewers. All authors approved her joining the manuscript.

\section{References}

1 Wilmoth JM, London AS. Aging veterans: Needs and provisions. In: Settersten R, Angel J, editors. Handbook of sociology of aging. New York (NY): Springer; 2011. p. 445-61.

2 Cohany SR. Labor force status of Vietnam-era veterans. Mon Labor Rev. 1987;110:11-7.

3 Marmar CR, Schlenger W, Henn-Haase C, Qian M, Purchia E, Li M, et al. Course of posttraumatic stress disorder 40 years after the Vietnam War: Findings from the National Vietnam Veterans Longitudinal Study. JAMA Psychiatry. 2015 Sep;72(9):875-81.

4 Card JJ. Lives after Vietnam: The personal impact of military service. Lexington (MA): Lexington Books; 1983.

5 London AS. Veterans and the life course. In: Harrington Meyer M, Daniele EA, editors. Gerontology: Changes, challenges, and solutions. Volume 1. Santa Barbara (CA): Praeger; 2016. p. 191-219.

6 Wilmoth JM, London AS, Parker WM. Military service and men's health trajectories in later life. J Gerontol B Psychol Sci Soc Sci. 2010 Nov;65(6):744-55.

7 Davison EH, Kaiser AP, Spiro A 3rd, Moye J, King LA, King DW. From late-onset stress symptomatology to later-adulthood trauma reengagement in aging combat veterans: taking a broader view. Gerontologist. $2016 \mathrm{Feb}$; 56(1):14-21.

8 Elder GH Jr, Clipp EC. Combat experience and emotional health: impairment and resilience in later life. J Pers. 1989 Jun;57(2):31141.

9 Anderson MC, Reinholz J, Kuhl BA, Mayr U. Intentional suppression of unwanted memories grows more difficult as we age. Psychol Aging. 2011 Jun;26(2):397-405.

10 Davison EH, Pless AP, Gugliucci MR, King LA, King DW, Salgado DM, et al. Late-life emergence of early-life trauma: the phenomenon of late-onset stress symptomatology among aging combat veterans. Res Aging. 2006;28(1):84-114.

11 King LA, King DW, Vickers K, Davison EH, Spiro A 3rd. Assessing late-onset stress symptomatology among aging male combat veterans. Aging Ment Health. 2007 Mar;11(2): 175-91.

12 Pless Kaiser A, Cook JM, Glick DM, Moye J. Posttraumatic stress disorder in older adults: A conceptual review. Clin Gerontol. 2019 JulSep;42(4):359-76.
13 Krause N. Lifetime trauma, emotional support, and life satisfaction among older adults. Gerontologist. 2004 Oct;44(5):615-23.

14 King DW, King LA, Foy DW, Keane TM, Fairbank JA. Posttraumatic stress disorder in a national sample of female and male Vietnam veterans: risk factors, war-zone stressors, and resilience-recovery variables. J Abnorm Psychol. 1999 Feb;108(1):164-70.

15 Schnur JB, Valdimarsdottir HB, Montgomery GH, Nevid JS, Bovbjerg DH. Social constraints and distress among women at familial risk for breast cancer. Ann Behav Med. 2004 Oct;28(2):142-8.

16 Steenkamp MM, Schlenger WE, Corry N, Henn-Haase C, Qian M, Li M, et al. Predictors of PTSD 40 years after combat: findings from the National Vietnam Veterans longitudinal study. Depress Anxiety. 2017 Aug;34(8):71122.

17 Burnell KJ, Coleman PG, Hunt N. Coping with traumatic memories: second World War veterans' experiences of social support in relation to the narrative coherence of war memories. Ageing Soc. 2010;30(1):57-78.

18 Kang S, Aldwin CM, Choun S, Spiro A 3rd. A life-span perspective on combat exposure and PTSD symptoms in later life: Findings from the VA Normative Aging Study. Gerontologist. $2016 \mathrm{Feb} ; 56(1): 22-32$.

19 Badr H, Barker TM, Milbury K. Couples' psychosocial adaptation to combat wounds and injuries. In: MacDermid Wadsworth S, Riggs D, editors. Risk and resilience in U.S. military families. New York (NY): Springer; 2010. p. 213-34.

20 Bodenmann G. Dyadic coping and its significance for marital functioning. In: Revenson TA, Kayser K, Bodenmann G, editors. Couples coping with stress: Emerging perspectives on dyadic coping. Washington (DC): American Psychological Association; 2005. p. 33-49.

21 Reis HT, Shaver P. Intimacy as an interpersonal process. In: Duck SW, Hay DF, Hobfoll SE, Ickes W, Montgomery BM, editors. Handbook of personal relationships: Theory, research and interventions. Oxford, England: John Wiley \& Sons; 1988. p. 367-89.

22 Campbell SB, Renshaw KD. PTSD symptoms, disclosure, and relationship distress: explorations of mediation and associations over time. J Anxiety Disord. 2013 Jun;27(5):494-502.
23 Nelson Goff BS, Hartman K, Perkins D, Summers K, Walker L, Monk JK. Talk to me: disclosure of past trauma experiences to spouses in military couples. J Veterans Stud. 2016; 1(1):98-128.

24 Carter SP, Renshaw KD, Curby TW, Allen ES, Markman HJ, Stanley SM. Protective buffering by service members during military deployments: associations with psychological distress and relationship functioning. Fam Process. 2019 Jan; https://doi.org/10.1111/ famp.12426.; Advance online publication.

25 Marini CM, MacDermid Wadsworth S, Franks MM, Wilson SR, Christ SL. Military spouses' self- and partner-directed minimization in the context of deployment. Mil Behav Health. 2019 Jul;7(3):245-56.

26 Balderrama-Durbin C, Snyder DK, Cigrang J, Talcott GW, Tatum J, Baker M, et al. Combat disclosure in intimate relationships: mediating the impact of partner support on posttraumatic stress. J Fam Psychol. 2013 Aug; 27(4):560-8.

27 Perlick DA, Sautter FJ, Becker-Cretu JJ, Schultz D, Grier SC, Libin AV, et al. The incorporation of emotion-regulation skills into couple- and family-based treatments for posttraumatic stress disorder. Mil Med Res. 2017 Jun;4(1):21-30.

28 Burnell KJ, Coleman PG, Hunt N. Falklands War veterans' perceptions of social support and the reconciliation of traumatic memories. Aging Ment Health. 2006 May;10(3):282-9.

29 Burland D, Lundquist JH. The best years of our lives: Military service and family relationships - A life-course perspective. In: Wilmoth JM, London AS, editors. Life course perspectives on military service. New York: Routledge; 2013. pp. 165-84.

30 Sheffler JL, Rushing NC, Stanley IH, SachsEricsson NJ. The long-term impact of combat exposure on health, interpersonal, and economic domains of functioning. Aging Ment Health. 2016 Nov;20(11):1202-12.

31 Jahn AL, Herman L, Schuster J, Naik A, Moye J. Distress and resilience after cancer in veterans. Res Hum Dev. 2012;9(3):229-47.

32 Danoff-Burg S, Revenson TA, Trudeau KJ, Paget SA. Unmitigated communion, social constraints, and psychological distress among women with rheumatoid arthritis. J Pers. 2004 Feb;72(1):29-46. 
33 Fekete EM, Stephens MA, Mickelson KD, Druley JA. Couples' support provision during illness: the role of perceived emotional responsiveness. Fam Syst Health. 2007;25(2): 204-17.

34 Antonucci TC, Fiori KL, Birditt K, Jackey LM Convoys of social relations: Integrating life span and life course perspectives. In: Freund AF, Lamb ML, Lerner RM, editors. Handbook of lifespan development. Hoboken (NJ): John Wiley and Sons; 2010. p. 434-73

35 Lang FR. Endings and continuity of social relationships: maximizing intrinsic benefits within personal networks when feeling near to death. J Soc Pers Relat. 2000;17(2):155-82.

36 Wrzus C, Hänel M, Wagner J, Neyer FJ. Social network changes and life events across the life span: a meta-analysis. Psychol Bull. 2013 Jan; 139(1):53-80.

37 Carstensen LL. Evidence for a life-span theory of socioemotional selectivity. Curr Dir Psychol Sci. 1995;4(5):151-6.

38 Burnell K, Needs A, Gordon K. Exploring the suitability and acceptability of peer support for older veterans. Qual Ageing Older Adults. 2017;18(2):120-30.

39 Fingerman KL. Consequential strangers and peripheral ties: the importance of unimportant relationships. J Fam Theory Rev. 2009; 1(2):69-86

40 Sixsmith J, Sixsmith A, Callender M, Corr S. Wartime experiences and their implications for the everyday lives of older people. Ageing Soc. 2014;34(9):1457-81.

41 Hunt N, Robbins I. World war II veterans, social support, and veterans' associations. Aging Ment Health. 2001 May;5(2):175-82.

42 Leedahl SN, Koenig TL, Ekerdt DJ. Perceived benefits of VFW post participation for older adults. J Gerontol Soc Work. 2011 Oct;54(7): $712-30$
43 Cappeliez P, O’Rourke N. Empirical validation of a model of reminiscence and health in later life. J Gerontol B Psychol Sci Soc Sci. $2006 \mathrm{Jul} ; 61(4): 237-44$.

44 Fiori KL, Antonucci TC, Cortina KS. Social network typologies and mental health among older adults. J Gerontol B Psychol Sci Soc Sci. 2006 Jan;61(1):25-32.

45 Carr D. Golden years? Social inequality in later life. New York (NY): Russell Sage Foundation; 2019. https://doi.org/10.7758/ 9781610448772.

46 Abbott KH, Stoller EP, Rose JH. The structure and function of frail male veterans' informal networks. J Aging Health. 2007 Oct; 19(5): 757-77.

$47 \mathrm{Li} \mathrm{T}$, Zhang Y. Social network types and the health of older adults: exploring reciprocal associations. Soc Sci Med. 2015 Apr;130:59-68.

48 Hogan DP. Transitions and social change: The early lives of American men. New York: Academic Press; 1981. https://doi.org/10. 1016/B978-0-12-352080-7.50022-7.

49 Wilmoth JM, London AS. The influence of military service on aging. In: George LK, Ferraro KF, editors. Handbook of aging and the social sciences. 8th ed. New York: Academic Press; 2016. p. 227-50.

50 Kelty R, Segal DR. The military as a transforming influence: Integration into or isolation from normal adult roles? In: Wilmoth JM, London AS, editors. Life course perspectives on military service. New York: Routledge; 2013. p. 19-47.

51 Keane TM, Scott WO, Chavoya GA, Lamparski DM, Fairbank JA. Social support in Vietnam veterans with posttraumatic stress disorder: a comparative analysis. J Consult Clin Psychol. 1985 Feb;53(1):95-102.
52 Brady CB, Pless Kaiser A, Spiro A 3rd, Davison E, King D, King L. Late-onset stress symptomatology (LOSS) scale - short form: development and validation. Aging Ment Health. 2019 Aug;23(8):952-60.

53 Cotten SR, Skinner KM, Sullivan LM. Social support among women veterans. J Women Aging. 2000;12(1-2):39-62.

54 Brown MT. Military service and lesbian, gay, bisexual, and transgender lives. In: Wilmoth J, London AS, editors. Life course perspectives on military service. New York: Routledge; 2013. pp. 97-118.

55 Brennan-Ing M, Seidel L, Larson B, Karpiak SE. Social care networks and older LGBT adults: challenges for the future. J Homosex. 2014;61(1):21-52.

56 Mays VM, Cochran SD. Mental health correlates of perceived discrimination among lesbian, gay, and bisexual adults in the United States. Am J Public Health. 2001 Nov;91(11): 1869-76.

57 Sherman MD, Kauth MR, Shipherd JC, Street RL Jr. Communication between VA providers and sexual and gender minority veterans: a pilot study. Psychol Serv. 2014 May;11(2):23542.

58 Kawachi I, Berkman LF. Social ties and mental health. J Urban Health. 2001 Sep;78(3): 458-67.

59 Wolf DA, Wing C, Lopoo LL. Methodological problems in determining the consequences of military service. In: Wilmoth J, London AS, editors. Life course perspectives on military service. New York: Routledge; 2013. pp. 25474.

60 Teachman J. Setting an agenda for future research on military service and the life course. In: Wilmoth J, London AS, editors. Life course perspectives on military service. New York: Routledge; 2013. p. 275-90. 